\title{
Research and Publication Ethics in Academia
}

\section{Hyejung Chang}

Editor of Healthcare Informatics Research, Kyung Hee University, Seoul, Korea

Research and publication ethics has recently been receiving considerable attention here in Asia due to controversies regarding fabricated diplomas, plagiarism, duplicate publications of academic papers, and theft of research findings. A common excuse heard from those accused is that many authors have done so in the past. Awareness of the gravity of these issues varies across different countries, and while Korea has made great strides in this area over the last couple decades, it still finds itself weeding out cases of ethical disregard. As editor-in-chief, I have had a fair share of ethically problematic manuscripts come my way, and I want to speak to this issue here.

The root of this phenomenon is arguably the nature of our institution. Many researchers are not given training in academic and research ethics during the course of their formal education. Thinking back on my childhood, I remember having only a vague notion that people should not cheat on exams, but that notion was always overshadowed by the more popular idea that true friends help their friends cheat.

I was naturally surprised when I first went to the United States in the 80's to pursue my graduate studies. Exams and assignments were taken with an intimidating level of seriousness, with warnings of severe punishments for cases of ethical infractions or suspicious behavior. Many universities identified cheating as an act worthy of expulsion, which would ultimately leave a black mark on a student's academic record that was almost impossible to erase. This environment did not seem out of the norm for my American coun-

This is an Open Access article distributed under the terms of the Creative Commons Attribution Non-Commercial License (http://creativecommons.org/licenses/bync/4.0/) which permits unrestricted non-commercial use, distribution, and reproduction in any medium, provided the original work is properly cited.

(C) 2020 The Korean Society of Medical Informatics terparts. The reason, I found, was that American students had been taught this ethical attitude from their days in grade school. These long-term reinforcements of moral rules and expectations clearly play a significant social role in the formation of our attitudes towards research and publication ethics.

In Korea, from the mid-2000s, as the international level of research has been conducted and their findings have been presented in global academic societies, the ethical awareness of researchers has been significantly improved to meet the needs of the international level. This improvement is due in part not only to efforts of researchers aiming to submit to high-level international journals but also to the globalization efforts of local journal editors. By reflecting the increasing international norms related to the research and publication ethics into their journals, editors are trying to prevent inappropriate academic activities and create an ethical research and publication environment.

Being indexed by Emerging Sources Citation Index (ESCI), Scopus, PubMed Central (PMC), and Korea Citation Index (KCI), Healthcare Informatics Research (HIR) has established and updated the Code of Ethics for stakeholders (authors, reviewers, editors, publishers, etc.) in relation to the publication of articles, with reference to best practice guidance from leading organizations around the world. The referenced guidance includes recommendations from the International Committee of Medical Journal Editors (ICMJE), together with the Committee on Publication Ethics (COPE) and the World Association of Medical Editors (WAME) [1-3]. This paper highlights the issues that have been found to be problematic in publishing HIR.

\section{Duplicate Publication}

For all manuscripts submitted to HIR, the manuscript 
should be original and not published previously or in the process of being considered for publication elsewhere. To avoid a duplicate publication, all authors must agree to the Authorship Responsibility and Copyright Transfer Form at the time of submission.

Duplicate publication may be justifiable only if the manuscript satisfies the six acceptable conditions of the ICMJE recommendations [1]. The most important criterion is the first: "The authors have received approval from the editors of both journals." Therefore, all or parts of duplicate publications are accepted only with the permission of the HIR Editorial Board. In particular, the following types of prior publication should be disclosed: "presentations at conferences" and "dissertations and theses."

\section{Plagiarism}

Many scholarly journals have adopted software tools to automatically detect plagiarism (as well as duplicate publication). HIR uses iThenticate (known as CrossCheck) to detect instances of overlapping and similar texts in submitted manuscripts against preexisting research papers and documents [4]. Although there is no absolute criterion to judge plagiarism from the results, HIR considers that an overall Similarity Index up to $15 \%-20 \%$ is acceptable with less than $1 \%-2 \%$ from each source [5]. The Content Tracking Report is also reviewed to consider the nature of the similarity. To avoid plagiarism, authors are encouraged to cite and acknowledge other sources appropriately.

\section{Authorship Problems}

All authors of a manuscript are responsible for the entirety of their content, meeting all four criteria in the HIR guideline. It is not easy for an editor to identify ghost, guest or gift authors, but there are cases where inquiries arise after publication of the paper as a result of conflicts between researchers. A complete authorship list must include individuals who contributed significantly to the study and are qualified for authorship. Gotzsche et al. [6] found that statisticians are often omitted in papers from industry-funded projects. A professional writer usually does not qualify as an author, but his or her involvement should be acknowledged using the ICMJE criteria [7].

In summary, this paper aims to help authors understand the integrity and ethical issues of research and publication in the process of research papers submitted to HIR. The research community is based on respect, consideration, solidarity, and strict ethics in conducting research, and furthermore, truth, objectivity, fairness, openness, and transparency are required of researchers, publishers, and peer reviewers in publishing and academic activities that share and spread research results. There is a growing demand for researchers to be more socially responsible and there are also more problems that expose them to the risk of conflict of interest. Due to the increased impact of research on society, a high level of ethical consciousness is required for authors who publish academic papers. It is expected that journals can serve as guides to enhance the ethical capacity of researchers.

\section{ORCID}

Hyejung Chang (http://orcid.org/0000-0002-5666-1305)

\section{References}

1. International Committee of Medical Journal Editors. Recommendations for the Conduct, Reporting, Editing, and Publication of Scholarly work in Medical Journals [Internet]. [place unknown]: International Committee of Medical Journal Editors; c2020 [cited at 2020 Jan 10]. Available from: http://www.icmje.org/recommendations/.

2. Committee on Publication Ethics. Principles of transparency and best practice in scholarly publishing [Internet]. Hampshire, UK: Committee on Publication Ethics; 2019 [cited at 2020 Jan 10]. Available from: https://publicationethics.org/resources/guidelines-new/principlestransparency-and-best-practice-scholarly-publishing.

3. World Association of Medical Editors. Policies for medical journal editors [Internet]. Bellagio, Italy: World Association of Medical Editors; c2016 [cited at 2020 Jan 10]. Available from: http://www.wame.org/policies.

4. iThenticate. Crossref similarity check powered by iThenticate [Internet]. Oakland (CA): iThenticate; c2019 [cited at 2020 Jan 10]. Available from: http://www.ithenticate. com/products/crossref-similarity-check.

5. iThenticate. CrossCheck plagiarism screening: understanding the similarity score [Internet]. Oakland (CA): iThenticate; 2011 [cited at 2020 Jan 10]. Available from: http://www.ithenticate.com/plagiarism-detection-blog/ bid/63534/CrossCheck-Plagiarism-Screening-Understanding-the-Similarity-Score.

6. Gotzsche PC, Hrobjartsson A, Johansen HK, Haahr MT, Altman DG, Chan AW. Ghost authorship in industryinitiated randomised trials. PLoS Med 2007;4(1):e19.

7. Wager E. Authors, ghosts, damned lies, and statisticians. PLoS Med 2007;4(1):e34. 